\title{
Investigation of the self-imaging position of a singlemode- multimode-singlemode optical fiber structure
}

Xianfan Wang

Harbin Engineering University

Elfed Lewis

University of Limerick

Pengfei Wang

Technological University Dublin, pengfei.wang@tudublin.ie

Follow this and additional works at: https://arrow.tudublin.ie/prcart

Part of the Electrical and Computer Engineering Commons

\section{Recommended Citation}

Wang, Pengfei \& Wang, Xianfan. (2017). Investigation of the self-imaging position of a singlemodemultimode-singlemode optical fiber structure. Microwave and Optical Technology Letters. 59. 1645-1651. 10.1002/mop.30605.

This Article is brought to you for free and open access by the Photonics Research Centre at ARROW@TU Dublin. It has been accepted for inclusion in Articles by an authorized administrator of ARROW@TU Dublin. For more information, please contact arrow.admin@tudublin.ie, aisling.coyne@tudublin.ie,gerard.connolly@tudublin.ie.

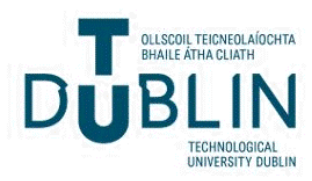


See discussions, stats, and author profiles for this publication at: https://www.researchgate.net/publication/317014109

\section{Investigation of the self-imaging position of a singlemodemultimode- singlemode optical fiber structure}

Article in Microwave and Optical Technology Letters · July 2017

DOI: 10.1002/mop.30605

CITATIONS

9

2 authors:

2. Pengfei Wang

Harbin Engineering University

332 PUBLICATIONS 4,162 CITATIONS

SEE PROFILE
READS

184

Xianfan Wang

Zhejiang University

27 PUBLICATIONS 254 CITATIONS

SEE PROFILE

Some of the authors of this publication are also working on these related projects:

Project Tapered optical fibres based sensors View project

Project Lasing in compound glass materials based microresonators View project 
TA B LE 2 Performance comparison of the proposed balun with other works

\begin{tabular}{lllllll} 
References & $\begin{array}{l}\text { Design } \\
\text { method }\end{array}$ & $\begin{array}{l}\text { Output } \\
\text { isolation }\end{array}$ & $\begin{array}{l}\text { Size } \\
\left(\mathbf{m m}^{2}\right)\end{array}$ & $\begin{array}{l}\text { Frequency } \\
\text { ratio }\end{array}$ & $\begin{array}{l}\text { Bandwidth } \\
\left(\left|\boldsymbol{S}_{\mathbf{1 1}}\right|>\mathbf{1 0} \mathbf{d B}, \mathbf{G H z}\right)\end{array}$ & $\begin{array}{l}\text { Flexible } \\
\text { implementation }\end{array}$ \\
\hline 5 & TDC $^{\mathrm{a}}$ & No & $16.8 \times 40.5$ & N/A & 0.08 & $\times$ \\
\hline 6 & CRLHTL $^{\mathrm{b}}$ & No & $29 \times 30.5$ & N/A & 1.25 & $\times$ \\
\hline 8 & BLS & No & $40 \times 55$ & N/A & N/A & $\times$ \\
\hline 9 & DSPSL & Exist & $51.9 \times 105$ & $1.62-3$ & $>0.10^{\text {c }}$ & $\checkmark$ \\
\hline This work & TSPSCL & Exist & $55 \times 70$ & $2.38-4.12$ & $1.30 / 0.62$ &
\end{tabular}

${ }^{\mathrm{a}}$ Trans-directional coupler.

${ }^{\mathrm{b}}$ Composite right/left handed transmission line.

${ }^{\mathrm{c}}\left|S_{11}\right|>15 \mathrm{~dB}$.

design. Therefore, this novel planar balun will be extensively utilized in dual-band radio frequency circuits and systems.

\section{ACKNOWLEDGMENTS}

This work was supported in part by National Key Basic Research Program of China (973 Program) (No. 2014CB339900), and National Natural Science Foundations of China (No. 61422103, No. 61671084, and No. 61327806).

\section{REFERENCES}

[1] Wang S, Chen PH. An active Marchand balun and its application to a 24-GHz CMOS mixer. IEEE Trans Comp Packag Manufact Tech. 2016;6:1535-1541.

[2] Ye Y, Yu B, Tang A, Drouin B, Gu QJ. A high efficiency Eband CMOS frequency doubler with a compensated transformerbased balun for matching enhancement. IEEE Microw Wireless Comp Lett. 2016;26:40-42.

[3] Jia H, Chi B, Kuang L, Wang Z. A W-band power amplifier utilizing a miniaturized Marchand Balun combiner. IEEE Trans Microw Theory Tech. 2015;63:719-725.

[4] Wang H, Zhang Z, Li Y, Feng Z. A wideband differential-fed slot antenna using integrated compact balun with matching capability. IEEE Trans Antennas Propag. 2014;62:5394-5399.

[5] Shie CI, Cheng JC, Chou SC, Chiang YC. Design of a new type planar balun by using trans-directional couplers. IEEE Trans Microw Theory Tech. 2012;60:471-476.

[6] Xu HX, Wang GM, Chen X, Li TP. Broadband balun using fully artificial fractal-shaped composite right/left handed transmission line. IEEE Microw Wireless Comp Lett. 2012;22:16-18.

[7] Ta HH, Pham AV. A compact boardband balun on multilayer organic substrate. Microw Opt Tech Lett. 2013;55: 1957-1959.

[8] Yang SY, Cho CS, Lee JW, Kim J. A novel dual-band balun using branch-lines with open stubs. Microw Opt Tech Lett. 2010;52:642-644.

[9] Dai GL, Wei XC, Li EP, Xia MY. Novel dual-band out-of-phase power divider with high power-handling capability. IEEE Trans Microw Theory Tech. 2012;60:2403-2409.
[10] Ren H, Shao J, Zhou M, Arigong B, Ding J, Zhang H. Design of dual-band transmission line with flexible phase shifts and its applications. Electron Lett. 2015;51:261-262.

[11] Katakam S, Ren H, Shao J, Zhou M, Arigong B, Ding J, Zhang H. A dual-band branch line coupler based on pi-shaped coupled lines. Microw Opt Tech Lett. 2015;57:501-504.

[12] Cao Y, Wen J, Hong H, Liu J. Design of planar dual-band branch-line coupler with $\pi$-shaped coupled lines. Prog Electromagn Res Lett. 2015;55:113-120.

[13] Zhang W, Wu Y, Liu Y, Yu C, Chen W. Compact coupled-line balun with complex impedances transformation and high isolation. IET Microw Antennas Propag. 2015;9:1587-1594.

How to cite this article: Yao L, Wu Y, Liu Y. Dualband balun with high isolation and flexible implementation based on three-section pi-shaped coupled lines. Microw Opt Technol Lett. 2017;59:1639-1645. https:// doi.org/10.1002/mop.30606

Received: 2 December 2016

DOI: $10.1002 /$ mop.30605

\section{Investigation of the self-imaging position of a singlemode- multimode-singlemode optical fiber structure}

\section{Xianfan Wang ${ }^{1}$ | Elfed Lewis ${ }^{2}$ | \\ Pengfei Wang1,3}

${ }^{1}$ Key Lab of In-fiber Integrated Optics, Ministry Education of China, Harbin Engineering University, Harbin 150000, China 
${ }^{2}$ Optical Fibre Sensors Research Centre, Department of Electronic and Computer Engineering, University of Limerick, Limerick, Ireland

${ }^{3}$ Photonics Research Centre, Dublin Institute of Technology, Kevin Street, Dublin 8, Ireland

\section{Correspondence}

Pengfei Wang, Photonics Research Centre, Dublin Institute of Technology, Kevin Street, Dublin 8, Ireland.

Email: pengfei.wang@dit.ie

\section{Funding information}

National Natural Science Foundation of China (NSFC), 61575050.

\begin{abstract}
In this paper, a theoretical and experimental investigation of the multimode interference induced self-imaging phenomenon in a singlemode-multimode-singlemode (SMS) fiber structure is described. The simulated transmission spectra based on guided modal propagation analysis and beam propagation method are presented and compared with experimental obtained results. The temperature dependence of the self-imaging position of the SMS fiber structure is also investigated. These investigations provide excellent opportunities for multiple future applications including telecommunications and sensing.

\section{KE Y W O R D S}

multimode interference, self-imaging position, temperature dependence
\end{abstract}

\section{1 | INTRODUCTION}

The SMS fiber structure has been widely investigated and is a relatively simple structure being a multimode fiber spliced between two single-mode fibers. It can be used as the basis for fabricating fiber optic sensors with a range of advantages such as ease of fabrication, high sensitivity, compact size, and potential low cost, ${ }^{1-4}$ which compares favorably with other technologies in fiber optic sensors including the fiber Bragg Grating (FBG) and long period grating (LPG). ${ }^{5,6}$

The SMS fiber structure is an excellent candidate for fiber optic sensing applications due to the existence of inherent multimode interference (MMI) in the multimode fiber (MMF), and this hybrid fiber structure can be developed as an edge filter, ${ }^{7}$ bandpass filter, ${ }^{8}$ as well as other optical fiber based photonic components by controlling the length and selecting the type of MMF sandwiched between two SMFs. Self-imaging, as a basic principle of the multimode interferometer (MMI) has been utilized to design a number of MMI based couplers, ${ }^{9}$ splitters, ${ }^{10}$ combiners, ${ }^{11}$ optical switches, ${ }^{12}$ and multi/demultiplexers. ${ }^{13}$ In addition to significant experimental progress, investigations of the theoretical aspects of MMI have recently been published.
In 1995, Soldano and Pennings demonstrated a theoretical analysis of the self-imaging properties in a planar multimode waveguide utilizing a guided modal propagation analysis (MPA), in which the formation of multiple re-imaging distance at certain lengths of MMI was successfully derived. ${ }^{14}$ Since then another analysis developed by Wang et al. ${ }^{15}$ using a numerical model based on the wide angle-beam propagation method (WA-BPM) through scanning the length of the MMF section has been demonstrated for theoretical prediction of the characteristics of MMI devices.

Over the past decade, the temperature dependence of the SMS fiber structure has also been widely investigated based on either wavelength encoding or intensity variation. ${ }^{2,16-20}$ The results of these investigations have shown that the thermo-optic coefficient (TOC) of MMF makes a more significant contribution to the temperature dependence of the SMS than that of the thermal expansion coefficient (TEC). To date no study of the temperature dependence of self-imaging properties within the MMF has been reported in the literature.

In this paper, a comparison between the theoretical models on the modeling of light propagation within the SMS fiber hybrid structure is presented, which has not been addressed in the literature. All analyses and predictions are verified numerically and experimentally. Additionally, a comprehensive investigation of the temperature dependence of self-imaging properties within the SMS fiber structure is presented. The temperature dependence of the SMS structure is investigated by monitoring the modal field distribution and the variation of the intensity of the output beam at the self-imaging position of the MMF.

\section{2 | COMPARISON OF MPA AND BPM ON THE CALCULATED SELF-IMAGING POSITION}

Figure 1 shows the basic structure of the SMS structure, which comprises a short length of MMF sandwiched between two standard SMFs. The significant parameters of the SMF are the radius of the core and cladding being 4.15 and $62.5 \mu \mathrm{m}$ respectively, and the refractive index of the core and cladding being 1.4504 and 1.4447 , respectively. In the case of the MMF, the radii of the core and cladding are 52.5 and $62.5 \mu \mathrm{m}$ respectively, and the refractive index of core and cladding is 1.4446 and 1.4271 , respectively.

The guided-modal propagation analysis (MPA) has been previously applied to this type of structure and widely used to analyze the light propagation characteristics and the spectral response within the SMS fiber structure. According to waveguide propagation theory within the SMS structure, the electric field can be expressed as ${ }^{21}$

$$
E(r, z)=\sum_{m=1}^{M} c_{\mathrm{m}} F_{\mathrm{m}}(r) \exp \left(i \beta_{\mathrm{m}} z\right)
$$




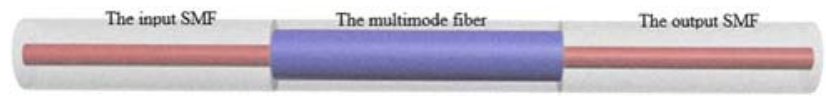

F I G URE 1 Schematic of SMS fiber structure [Color figure can be viewed at wileyonlinelibrary.com]

$$
L_{\mathrm{s}}(z)=10 \log _{10}\left(\left|\sum_{m=1}^{M} c_{\mathrm{m}}^{2} \exp \left(i \beta_{\mathrm{m}} z\right)\right|^{2}\right)
$$

where $c_{\mathrm{m}}$ is the excitation coefficient of the $m$ th eigenmode, $M$ is the excited mode number of the $\mathrm{LP}_{0 \mathrm{~m}}$ multimode fiber, and $\beta_{\mathrm{m}}$ is the propagation constant of the $m$ th eigenmode of the multimode fiber.

Using Equations 1 and 2, the spatial optical intensity distribution within the MMF can be obtained as shown in Figure 2. It is seen that the intensity changes as the light propagates along the $\mathrm{MMF}$, and reaches a maximum within the axial distance range of $[40,000,45,000](\mu \mathrm{m})$, which corresponds to the self-imaging position.

In order to obtain a comparison with the simulated results using MPA, the Beam PROP simulation engine (a part of RSoft Component Design Suite) based on the wide-angle beam propagation method (WA-BPM) was used to simulate the light transmission within the MMF. In order to achieve a more accurate simulated result, the Padé order $(3,3)$ and the boundary condition of perfectly matched layer (PML) were adopted. When an eigenmode of the SMF at the wavelength of $1550 \mathrm{~nm}$ is used as the input field, it is possible to calculate the field amplitude distribution of propagation within the MMF and this is shown in Figure 3. The maximum field intensity was also found to occur in the range of $[40,000,50,000]$. Furthermore, the transmission of the SMS fiber structure was calculated and the approximate theoretical relationship between transmission loss and MMF length was obtained as ${ }^{15}$

$$
L_{\mathrm{S}}(l)=10 \log _{10}\left[\frac{\left|\int_{0}^{\infty} E(l, r) F(r) r \mathrm{~d} r\right|^{2}}{\int_{0}^{\infty}|E(l, r)|^{2} r \mathrm{~d} r \int_{0}^{\infty}|F(r)|^{2} r \mathrm{~d} r}\right]
$$

where $l$ is MMF length, $E(l, r)$ is the calculated field at the interface between the MMF section and the output SMF, and $F$ $(r)$ is the eigenmode of the output SMF.

Based on Equations 2 and 3, the transmission loss as a function of the length of the MMF was calculated and the result shown in Figure 4. From Figure 4, it is clear that a very small discrepancy exists between the calculated transmission spectra using MPA and BPM. Specifically, for the calculated results using the MPA method, the self-imaging position occurs at an axial position of $42,877 \mu \mathrm{m}$ with a loss of $-0.25 \mathrm{~dB}$, while for that of the BPM, the self-imaging position is at $43,125 \mu \mathrm{m}$ with a loss of $-0.633 \mathrm{~dB}$ along the propagation direction of the MMF.

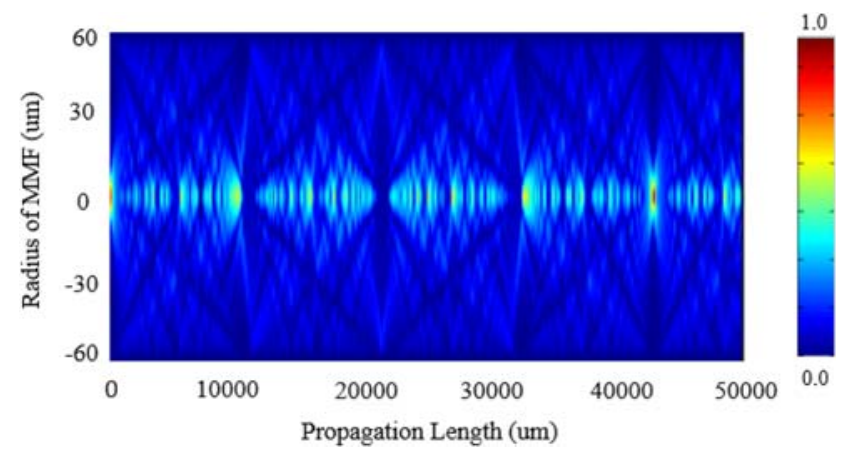

FIG URE 2 Optical intensity distribution within MMF using MPA [Color figure can be viewed at wileyonlinelibrary.com]

\section{3 | EXPERIMENTAL DETERMINATION OF THE TRANSMISSION SPECTRAL OF THE SMS}

Two identical SMS fiber samples were fabricated using a short piece of MMF about 43,000 $\mu \mathrm{m}$ spliced between two SMFs using a commercial fusion splicer (Fujikura 62S). The MMF lengths were initially approximately determined using a high precision cleaver (Fujikura CT-32), then accurately controlled by polishing using high grade fiber polishing papers. Finally, the length of the MMF of the first SMS sample was accurately set to $42877 \mu \mathrm{m}$, the self-imaging position as predicted by the MPA simulation. The MMF length of the second SMS sample was similarly set to $43125 \mu \mathrm{m}$, the selfimaging position predicted by the WA-BPM simulation. Figure 5 shows the experimental setup for measuring the transmission spectra of the SMS fiber sample. A Broadband Source (NKT) was used for launching the light signal into the SMS fiber samples and the optical spectrum analyzer (OSA) was used for recording the transmission spectra received. In Figure 6, the red dot line represents the transmission optical spectrum of the first SMS fiber sample. It is clear from Figure 6 that the central wavelength (the wavelength of minimum transmission loss) is located around $1549 \mathrm{~nm}$. The black solid line represents the transmission optical spectrum of the second SMS fiber sample, and the central wavelength

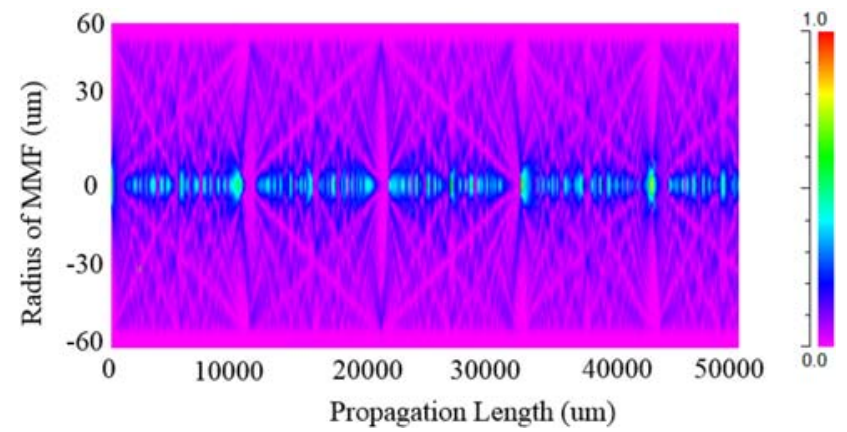

FIG URE 3 Optical intensity distribution within MMF using WABPM [Color figure can be viewed at wileyonlinelibrary.com] 


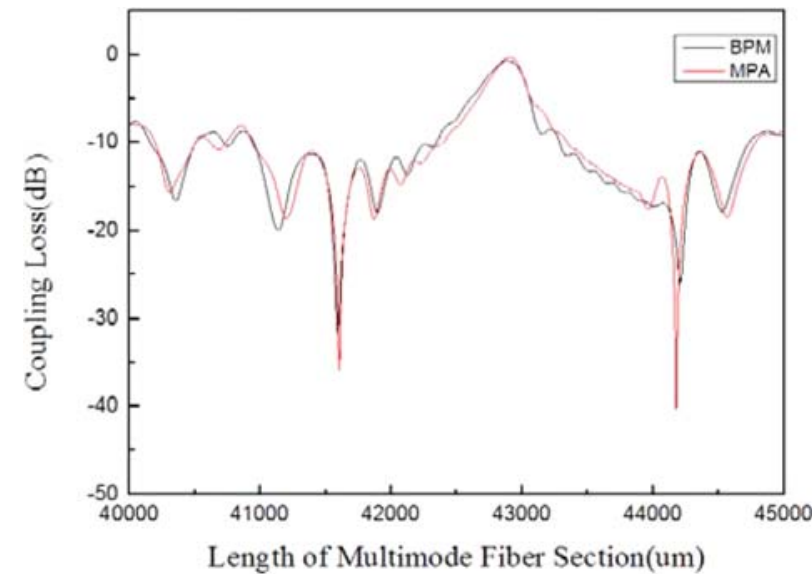

F IG URE 4 Comparison of the self-imaging phenomenon utilizing MPA (red line) and BPM (black line) [Color figure can be viewed at wileyonlinelibrary.com]

in this case is located close to $1545 \mathrm{~nm}$. The results of Figure 6 indicate that the discrepancy between the experimental and the calculated self-imaging position using the MPA method is much smaller than that of the BPM. Therefore, the MPA method was selected for determining the self-imaging position of the SMS structure in the investigation described in this article.

\section{4 | TEMPERATURE DEPENDENCE OF SELF-IMAGING PROPERTIES OF THE SMS FIBER STRUCTURE}

The results of Figures 2-4 indicate that the self-imaging position plays a key role in determining the light propagation characteristics of the SMS fiber structure, and the MPA model provides the most accurate numerical vehicle for analysis and prediction of the SMS device performance.

The temperature dependence of the SMS fiber structure is well known and has been widely investigated over the past decade, but is exclusively based on wavelength shift or intensity variation monitored by an optical spectrum analyzer. The effect of temperature on the SMS fiber structure arises mainly from the temperature dependence of the refractive index and physical dimensional changes of the fiber core and cladding. These changes can be determined by thermo-optic coefficient (TOC) and the thermal expansion coefficient (TEC). The changes in core radius $(R)$, MMF length $(L)$, and refractive index $(n)$ as a function of temperature variation $(\Delta T)$ can be expressed as follows ${ }^{16}$

$$
\begin{gathered}
R_{(\mathrm{SMF}, \mathrm{MMF}) \mathrm{T}}=R_{(\mathrm{SMF}, \mathrm{MMF}) 0}+\alpha \cdot R_{(\mathrm{SMF}, \mathrm{MMF}) 0} \cdot \Delta T \\
L_{(1,2) \mathrm{T}}=L_{(1,2) 0}+\alpha \cdot L_{(1,2) 0} \cdot \Delta T \\
n_{(\text {core, clad }) \mathrm{T}}=n_{(\text {core, } \text { llad }) 0}+\xi \cdot n_{(\text {core, }, \text { lad }) 0} \cdot \Delta T
\end{gathered}
$$

where $\alpha$ and $\xi$ are the TEC and TOC, respectively. In the case of the fiber types used in the structure of this investiga-

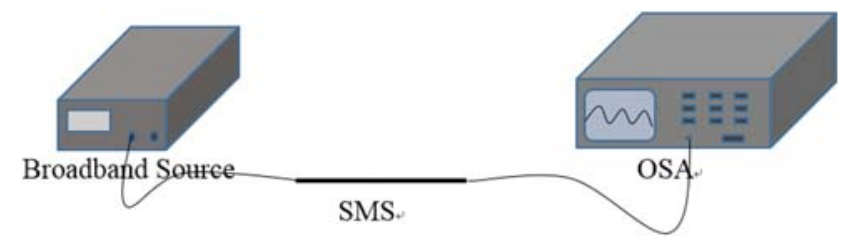

FIGURE 5 Experimental setup for measuring the transmission spectrum of SMS [Color figure can be viewed at wileyonlinelibrary.com]

tion, $\alpha=5 \times 10^{-7} /{ }^{\circ} \mathrm{C}$ and $\xi=6.9 \times 10^{-6} /{ }^{\circ} \mathrm{C}$ for both the $\mathrm{SMF}$ and MMF. It is evident that the TOC has a greater effect on the parameters of the SMS fibers than the TEC.

The temperature dependent transmission spectrum of the SMS Structure can be simulated using the MPA method taking the TOC and TEC into consideration. The relationship between transmission losses @ $1550 \mathrm{~nm}$ as a function of propagation distance in the axial region very close to the self-imaging position at the different temperatures is shown in Figure 7. Figure 7A shows the transmission loss in close proximity to the self-imaging position for a temperature range 20 to $100^{\circ} \mathrm{C}$ with an interval of $20^{\circ} \mathrm{C}$. It is clear that there is a significant shift in the self-imaging position with changing temperature. It is also clear from Figure 7B, that the shift in self imaging position is a near ideal linear relationship with the temperature, having a linear regression coefficient value $R^{2}=1.0000$, and its slope is $0.3215 \mu \mathrm{m} /$ ${ }^{\circ} \mathrm{C}$. A knowledge of the self-imaging position can therefore be a useful tool to investigate the temperature dependent performance of the SMS fiber structure.

Using the MPA method, the output beam profile at the self-imaging position of the MMF fiber has been investigated, the length of the MMF in the simulation being chosen as $42,877 \mu \mathrm{m}$ where self-imaging phenomenon is known to occur. The calculated 2D and 3D modal field distribution, calculated as normalized intensity referred to a maximum value of $3.29 \mathrm{~dB}$ at a temperature of $20^{\circ} \mathrm{C}$ and $100^{\circ} \mathrm{C}$, are shown in Figure 8. From the simulated results in Figure 8A-D, it is clear

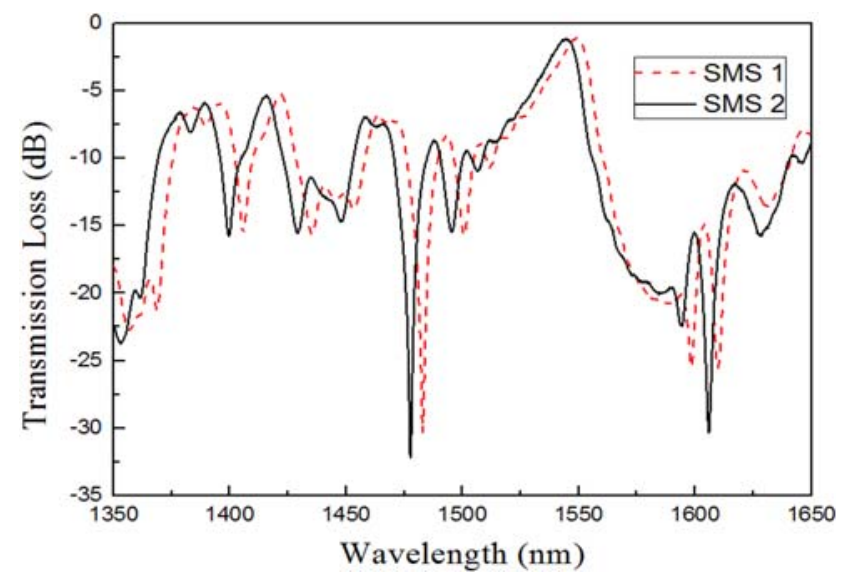

FIG URE 6 Measured transmission spectra of the studied SMS fibers [Color figure can be viewed at wileyonlinelibrary.com] 


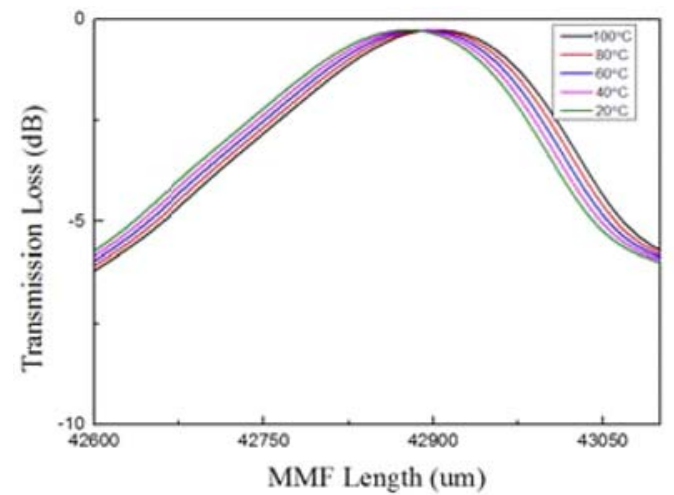

(A)

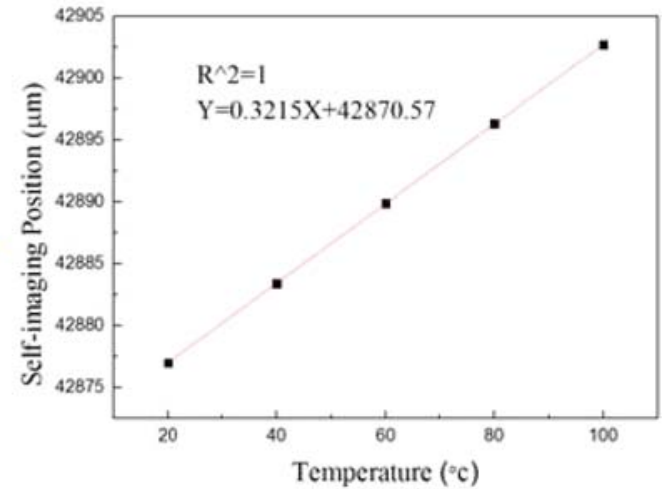

(B)

FIGURE 7 (A) The transmission spectra around self-imaging position at the different temperatures; (B) self-imaging position as a function of temperature and its linear fit [Color figure can be viewed at wileyonlinelibrary.com]

that it has a maximum intensity of $-0.25 \mathrm{~dB}$ at the temperature of $20^{\circ} \mathrm{C}$ and as the temperature increases, the intensity decreases to $-0.35 \mathrm{~dB}$ when the temperature increases to $100^{\circ} \mathrm{C}$.

To verify the simulated results, the length of MMF was set at the self-imaging distance about $42,877 \mu \mathrm{m}$ and spliced with a single SMF, forming an SMF-MMF fiber structure. A tunable laser (Santec TSI-710) was used as the light source for launching the signal to the SMF-MMF structure at the source's wavelength of $1550 \mathrm{~nm}$, the SMF-MMF fiber struc-

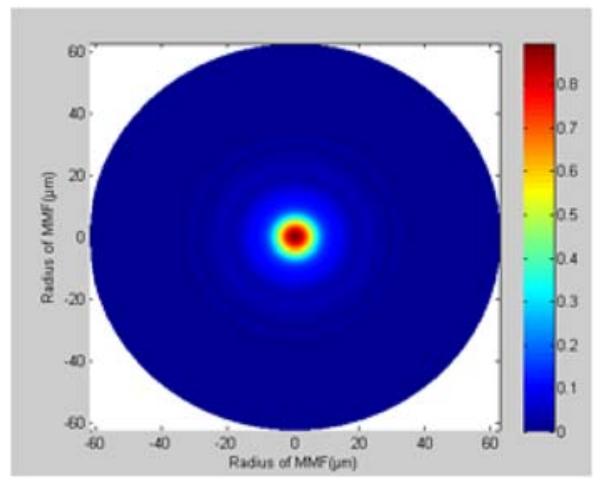

(A)

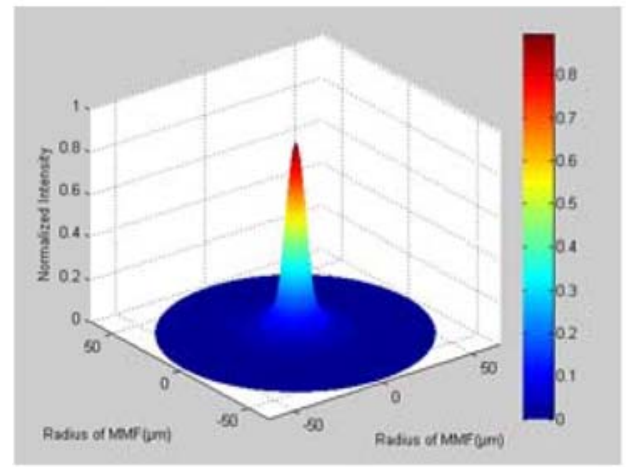

(C) ture was placed on a thermoelectric Peltier cooler who's temperature was accurately controlled using a current controller (TTi, TSX3510P) as shown in Figure 9. A three-dimensional high precision translation stage with a displacement resolution of $50 \mathrm{~nm}$ was used to adjust the position of the cooler along with the MMF fiber. The output light of the MMF was projected to a laser beam profiler (CCD, Newport), which was connected with a windows computer for monitoring the output modal field distribution, and the typical output is shown in Figure 10. In addition, an optical power meter was

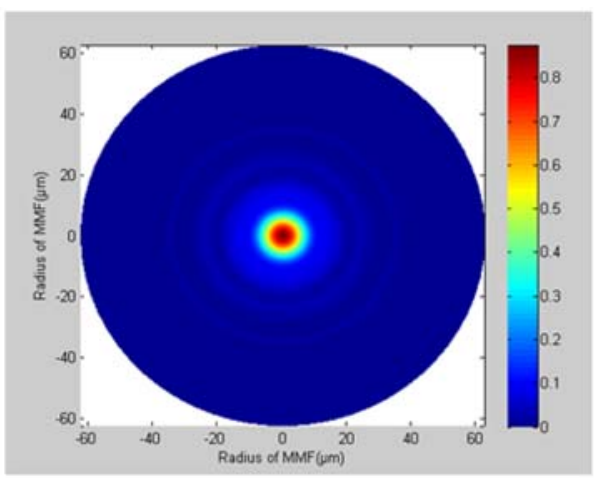

(B)

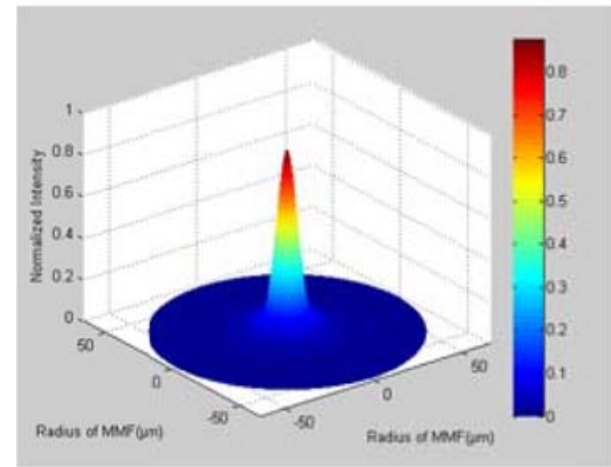

(D)

F I G URE 8 (A) and (C) 2D/3D modal field distribution at 20 ${ }^{\circ}$; (B) and (D) 2D/3D modal field distribution at $100^{\circ} \mathrm{C}[$ Color figure can be viewed at wileyonlinelibrary.com] 


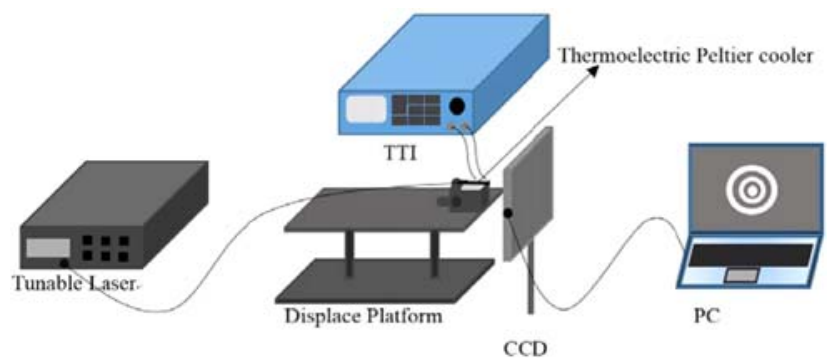

F I G URE 9 Schematic of experimental set-up measuring modal field distribution [Color figure can be viewed at wileyonlinelibrary.com]

placed at the end of the SMF-MMF fiber structure and was used to measure the optical intensity variations at the wavelength of $1550 \mathrm{~nm}$ at different temperatures. Figure 11 shows the output intensity as a function of temperature in the range $20-100^{\circ} \mathrm{C}$. It indicates that the output intensity decreases when the surrounding temperature increases, and the measured results agree well with the simulated results (shown in Figure 8).

From Figure 10A,B and C,D, it is clear that at room temperature $\left(20^{\circ} \mathrm{C}\right)$, the captured modal field has a maximum intensity of $-7.849 \mathrm{~dB}$, because it is closest to the modal field distribution maximum at the self-imaging position. When temperature increases to $100^{\circ} \mathrm{C}$, the measured intensity drops to $-8.733 \mathrm{~dB}$ because of the redshifts of the selfimaging position of the MMF. To better evaluate the difference between the theoretical model and the measured results presented in Figures 9 and 10, the optical intensities at a fixed wavelength as a function of different temperature was measured. Figure 11 shows both measured and simulated optical intensities at the wavelength of $1550 \mathrm{~nm}$ as a function

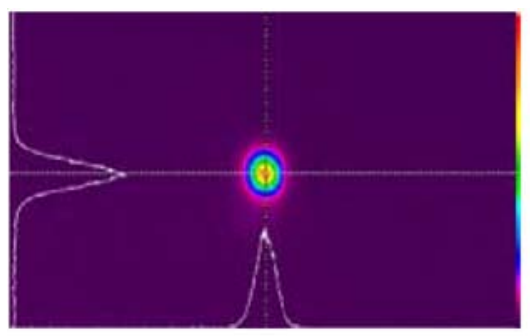

(A)

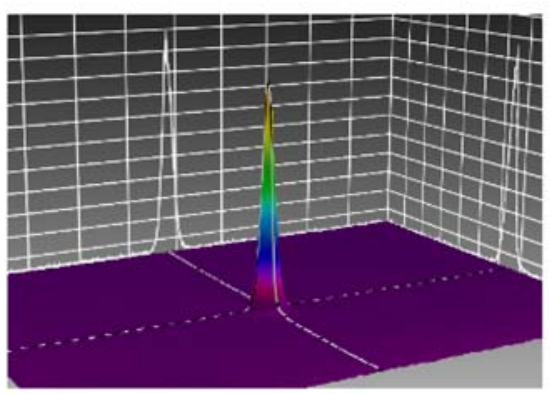

(C)

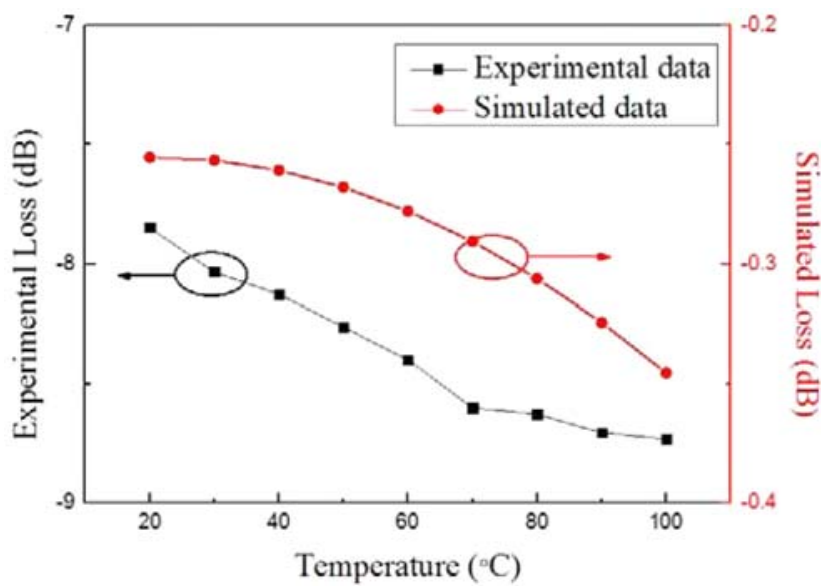

F IG URE 11 The optical intensities at a wavelength of $1550 \mathrm{~nm}$ as a function of temperatures $\left(20-100^{\circ} \mathrm{C}\right)$ [Color figure can be viewed at wileyonlinelibrary.com]

of the ambient temperature ranging from 20 to $100^{\circ} \mathrm{C}$ with an interval of $10^{\circ} \mathrm{C}$. From Figure 11, it is clear that there is general agreement, about $90 \%$ in difference between the measured results and simulated data. The discrepancy between the theoretical and experimental results are mainly caused by several impact factors, for example, airflow induced temperature vibrations and the resolution of the $\mathrm{CCD}$ etc.

\section{CONCLUSION}

The multimode interference induced self-imaging phenomenon in the SMS fiber structure has been studied numerically and experimentally in this work. Detailed comparisons

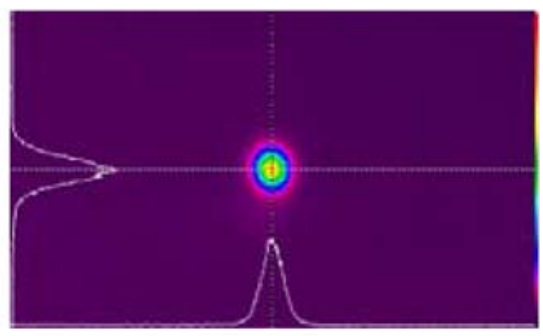

(B)

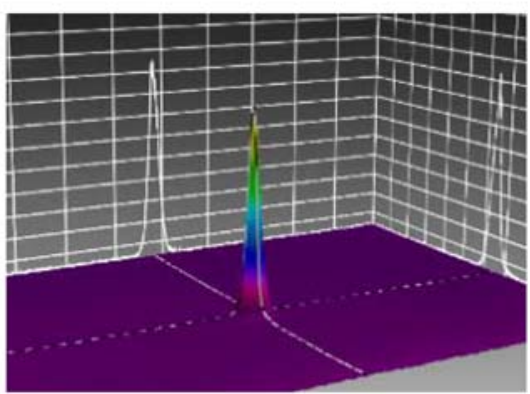

(D)

FIGURE 10 (A) and (C) 2D/3D modal field distribution at the room temperature (20 $\left.{ }^{\circ} \mathrm{C}\right)$; (B) and (D) 2D/3D modal field distribution at $100^{\circ} \mathrm{C}[\mathrm{Color}$ figure can be viewed at wileyonlinelibrary.com] 
between theoretical and experimental results have been carried out to investigate the accuracy of two different models based on the WA-BPM and MPA. The temperature dependence of the SMS fiber structure has also been investigated theoretically and experimentally. The good agreement between the experimental and simulated results indicates that the approximated guided-MPA method is superior when used to evaluate the optical performance of the SMS fiber structure or other multimode interference based photonic devices. The temperature dependent self-imaging behavior may offer excellent opportunities for multiple future applications including telecommunications, near-field micro-scanning/manipulation and compact sensing systems.

\section{ACKNOWLEDGMENTS}

This work was supported by the National Natural Science Foundation of China (NSFC) under grant 61575050; This work was also supported by the 111 project (B13015), to the Harbin Engineering University.

\section{REFERENCES}

[1] Kumar A, Varshney RK, Antony S, Sharma P. Transmission characteristics of SMS fiber optic sensor structures, Opt Commun. 2003;219:215-219.

[2] Hatta AM, Rajan G, Semenova Y, Farrell G. SMS fibre structure for temperature measurement using a simple intensity-based interrogation system. Electron Lett. 2009;45:1069-1070.

[3] Wang PF, Brambilla G, Ding M, Semenova Y, Wu Q, Farrell G. Investigation of single-mode-multimode-single-mode and single-mode-tapered-multimode-single-mode fiber structures and their application for refractive index sensing. J Opt Soc Am B Opt Phys. 2011;28:1180-1186.

[4] Wu Q, Semenova Y, Yan B, et al. Fiber refractometer based on a fiber Bragg grating and single-mode-multimode-single-mode fiber structure. Opt Lett. 2011;36:2197-2199.

[5] Haran FM, Rew JK, Foote PD. A strain-isolated fibre Bragg grating sensor for temperature compensation of fibre Bragg grating strain sensors. Meas Sci Technol. 1998;9:1163.

[6] Chen S, Tong Z, Zhao Q, Liu Z, Dong X. A smart bending sensor with a novel temperature-and strain-insensitive long-period grating. Sens Actuat A Phys. 2004;116:103-106.

[7] Wang C, Farrell G. Multimode-fiber-based edge filter for optical wavelength measurement application and its design. Microw Opt Technol Lett. 2006;48:900-902.

[8] Mohammed WS, Smith PWE, Gu XJ. All-fiber multimode interference bandpass filter. Opt Lett. 2006;31:2547-2549.

[9] Emkey WL, Jack CA. Multimode fiber-lens optical coupler. Google Patents 1987.

[10] Hibino Y, Hanawa F, Nakagome H, Ishii M, Takato N. High reliability optical splitters composed of silica-based planar lightwave circuits. J Lightwave Technol. 1995;13:1728-1735.

[11] Berman AL. Optical combiner collimating apparatus. Google Patents 1991.
[12] Tanabe T, Notomi M, Mitsugi S, Shinya A, Kuramochi E. Fast bistable all-optical switch and memory on a silicon photonic crystal on-chip. Opt Lett. 2005;30:2575-2577.

[13] Nosu K, Ishio H, Miki T. Optical multiplexer and demultiplexer. Google Patents 1981.

[14] Soldano LB, Pennings EC. Optical multi-mode interference devices based on self-imaging: Principles and applications. J Lightwave Technol. 1995;13:615-627.

[15] Wang Q, Farrell G. All-fiber multimode-interference-based refractometer sensor: Proposal and design. Opt Lett. 2006;31:317-319.

[16] Hatta AM, Semenova Y, Rajan G, Wang P, Zheng J, Farrell G. Analysis of temperature dependence for a ratiometric wavelength measurement system using SMS fiber structure based edge filters. Opt Commun. 2010;283:1291-1295.

[17] Li EB, Peng GD. Wavelength-encoded fiber-optic temperature sensor with ultra-high sensitivity. Opt Commun. 2008;281:5768-5770.

[18] Li E. Temperature compensation of multimode-interferencebased fiber devices. Opt Lett. 2007;32:2064-2066.

[19] Tripathi SM, Kumar A, Varshney RK, Kumar YBP, Marin E, Meunier JP. Strain and temperature sensing characteristics of single-mode-multimode-single-mode structures. $J$ Lightwave Technol. 2009;27:2348-2356.

[20] Zhao Y, Cai L, Li XG. High sensitive modal interferometer for temperature and refractive index measurement. IEEE Photon Technol Lett. 2015;27:1341-1344.

[21] Wang Q, Farrell G, Yan W. Investigation on single-modemultimode single-mode fiber structure, Journal of Lightwave Technology 26 (2008), 512-519.

How to cite this article: Wang $\mathrm{X}$, Lewis E, Wang P. Investigation of the self-imaging position of a singlemode-multimode-singlemode optical fiber structure. Microw Opt Technol Lett. 2017;59:1645-1651. https://doi.org/10.1002/mop.30605

Received: 4 December 2016

DOI: $10.1002 /$ mop.30599

\section{Miniaturized high-band UWB array antenna}

\author{
Fumiya Iwai $^{1}$ | Kuniaki Yoshitomi ${ }^{2}$ | \\ Haruichi Kanaya ${ }^{1}$ \\ ${ }^{1}$ Department of Electronics, Kyushu University, Fukuoka 819-0395, Japan \\ ${ }^{2}$ E-JUST Center, Kyushu University, Fukuoka 819-0395, Japan
}

Correspondence

Haruichi Kanaya, Department of Electronics, Kyushu University, Fukuoka 819-0395, Japan.

Email: kanaya@ed.kyushu-u.ac.jp 